\title{
A New Approach for Adipose Tissue Treatment and Body Contouring Using Radiofrequency-Assisted Liposuction
}

\author{
Malcolm Paul $\cdot$ Robert Stephen Mulholland
}

Received: 15 January 2009/ Accepted: 16 March 2009/Published online: 19 June 2009

(c) The Author(s) 2009. This article is published with open access at Springerlink.com

\begin{abstract}
A new liposuction technology for adipocyte lipolysis and uniform three-dimensional tissue heating and contraction is presented. The technology is based on bipolar radiofrequency energy applied to the subcutaneous adipose tissue and subdermal skin surface. Preliminary clinical results, thermal monitoring, and histologic biopsies of the treated tissue demonstrate rapid preaspiration liquefaction of adipose tissue, coagulation of subcutaneous blood vessels, and uniform sustained heating of tissue.
\end{abstract}

Keywords Coagulation - Liposuction · Radiofrequency · Tightening

We live in a culture preoccupied with both weight and body contour. North America also is a society in which obesity is an epidemic. It is no surprise then that liposuction continues to be the most commonly performed aesthetic procedure in the world. In 2007, 450,000 liposuction procedures were performed in the United States alone by board-certified plastic surgeons, and another 150,000 by nonplastic surgeon physicians, for a total 600,000 lipocontouring procedures, accounting for approximately $5 \%$ of all elective surgeries in the United States. It is estimated that the number of

\footnotetext{
M. Paul ( $($ )

Aesthetic Plastic Surgery Institute, University of California, Irvine, CA 92660, USA

e-mail: mpaulmd@hotmail.com

R. S. Mulholland

Private Aesthetic Plastic Surgery Practice, SpaMedica Canada, 66 Avenue Rd., Suite 4, Toronto, ON M5R 3N8, Canada

e-mail: mulhollandmd@spamedica.com
}

liposuction procedures will more than double over the next 5 years.

Coincident with the dramatic rise in liposuction procedures, the aging "baby boomer" population, with decreasing skin tone and advanced laxity, are seeking body contour procedures. A technology that effectively allows the physician to remove and contour adipose tissue with less bruising, swelling, and pain while simultaneously providing for significant soft tissue contraction would enjoy popular appeal.

Traditional tumescent, small-cannula, suction-assisted liposuction (SAL) is based on mechanical disruption of adipose tissue by a suction cannula moved manually through the subcutaneous space aspirating small fat clusters of adipose tissue through the openings in the cannula $[4,9,11,12,21]$. This traditional liposuction procedure of avulsing fat through a mechanically induced negative pressure requires a degree of effort on the part of the physician and can be quite traumatic for the patient.

Traditional SAL is less effective in secondary liposuction procedures and in fibrous areas, which do not enjoy significant skin contraction $[13,14]$. The evolution of smaller vented cannulas, wetting solutions, and syringe aspiration techniques has refined the art of liposuction [5-7, 13, 14, 16$18,22]$. In an attempt to improve the postoperative patient recovery profile of pain, swelling, and bruising, and to enhance skin contraction, physician effort, and effectiveness in secondary and fibrous cases, newer generations of energyassisted liposuction technologies have been developed.

The technique of ultrasound-assisted liposuction, in which cavitational ultrasound energy is delivered through a probe to adipose tissue specifically cavitated and liquified, is shown to be less traumatic than SAL and may result in more skin contraction [2, 15, 20, 23, 24]. Power-assisted liposuction (PAL) is a commonly used technology that uses a variable-speed motor to provide reciprocating motion to 
the cannula, which in combination with the reciprocating action of the surgeon's arm, facilitates removal of adipose tissue [3]. The principal advantage of PAL is treatment speed and economy of motion.

Most recently, laser-assisted lipolysis (LAL) has been popularized $[1,8,10,19]$. With the LAL technique, small fiberoptic probes deliver thermal and micromechanical lipolysis to adipose tissue, reducing the need for traumatic adipose aspiration forces and pressures and leading to an improved recovery profile for the patient. One of the purported LAL benefits is enhanced skin contraction after application of the small fiber to the subdermal space and warming of the skin to a temperature of $40^{\circ} \mathrm{C}[1,8,10,19]$.

Although LAL became popular because of a strong campaign directly to consumers highlighting diminished recovery pain and risk as well as the potential ability to tighten the skin through subdermal heating, its use remains limited by relatively slow treatment speed, poor control of heating uniformity, and risk of tissue burns.

The radiofrequency-assisted liposuction (RFAL) technique described in this report offers

- Faster treatment

- Reduced tissue trauma

- Improved safety

- Uniform heating of the skin and the subcutaneous layer

- Potential skin contraction.

\section{Materials and Methods}

The RFAL procedure was performed for 20 patients and 40 lipoplasty zones. The average age of the 18 women and 2 men was 43.9 years (range, 17-56 years). All RFAL areas underwent tumescent anesthesia before application of the radiofrequency (RF) energy. All aspiration was performed using a standard blunt-nose Mercedes cannula (Grahams Medical Corp, Costa Mesa, CA) (2.4-3.7 mm). The body areas treated included hips $(n=16)$, abdomen $(n=14)$, outer $(n=2)$ and inner $(n=4)$ thighs, arms $(n=1)$, love handles $(n=2)$, and male breasts $(n=2)$ (Table 1$)$.

Table 1 Treated areas

\begin{tabular}{lc}
\hline Zone & No. of cases \\
\hline Hips & 16 \\
Abdomen & 14 \\
Outer & 2 \\
Inner thighs & 4 \\
Arms & 1 \\
Love handles & 2 \\
Male breast & 1 \\
\hline
\end{tabular}

The RFAL body contour procedure was performed using the BodyTite system (Invasix Ltd, Yokneam, Israel). The BodyTite system's bipolar RF handpiece is inserted into the subcutaneous tissue, as shown in Fig. 1. The internal electrode is inserted into the adipose tissue at the desired depth for adipose and blood vessel coagulation. This insulated internal electrode probe emits the RF current through a small conductive tip. The external electrode has a larger contact area and is applied to the skin surface, creating lower power density in the skin than in the adipose tissue. Up to $50 \mathrm{~W}$ of RF power is applied between the two electrodes. The RF power distribution between the electrodes is shown schematically in Fig. 2. The RF current creates heat and coagulates the adipose, vascular, and fibrous tissue in the operative area.

In this study, electrode size and applied power were adjusted to provide adipose tissue liquefaction in the tissue between the internal and external electrodes and subnecrotic heating in the skin. Online, continuous skin temperature measurements with a negative feedback loop control of power were conducted by a temperature sensor embedded in the external electrode and confirmed by thermal camera FLIR A320 (FLIR Systems, Sausalito, CA).

Continuous online tissue impedance and power output between electrodes were monitored. During treatment, the parameters of the BodyTite device were set so that the system would reach $40^{\circ} \mathrm{C}$ and maintain that target temperature for 1 to $2 \mathrm{~min}$. The typical RF energy introduced into the treated area was $100 \mathrm{~J} / \mathrm{cm}^{2}$. Uniformity of temperature distribution was analyzed using thermal images and Researcher 2.9 of Flir Systems software.

In addition, two patients underwent RFAL to their lower abdominal tissue immediately before excision of this tissue through an abdominoplasty procedure. Several 6-mm excisional biopsies were taken at the end of the treatment to analyze the RFAL treatment effect on fat and skin. A control biopsy was taken from an immediately adjacent untreated area.

The objective of the study was to establish the range of optimal treatment parameters and the RFAL treatment technique for different anatomic zones and thicknesses of the fat layer. The main success indicators were

- Safe treatment

- Fast treatment

- Easy technique

- Uniform temperature distribution $\left( \pm 2^{\circ} \mathrm{C}\right)$

- Ability to maintain desired contraction temperatures for a consistent duration of time

- Coagulation and liquefaction of adipose tissue

- Blood vessel coagulation in the adipose layer.

The areas to be contoured were divided into distinct thermal zones of $10 \times 15 \mathrm{~cm}$. The discrete thermal zones 
Fig. 1 Bipolar radiofrequency handpiece inserted into the body

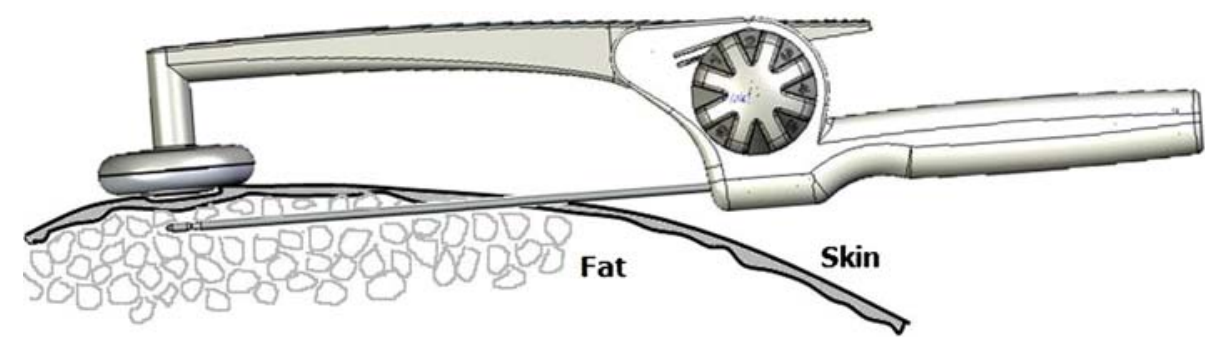

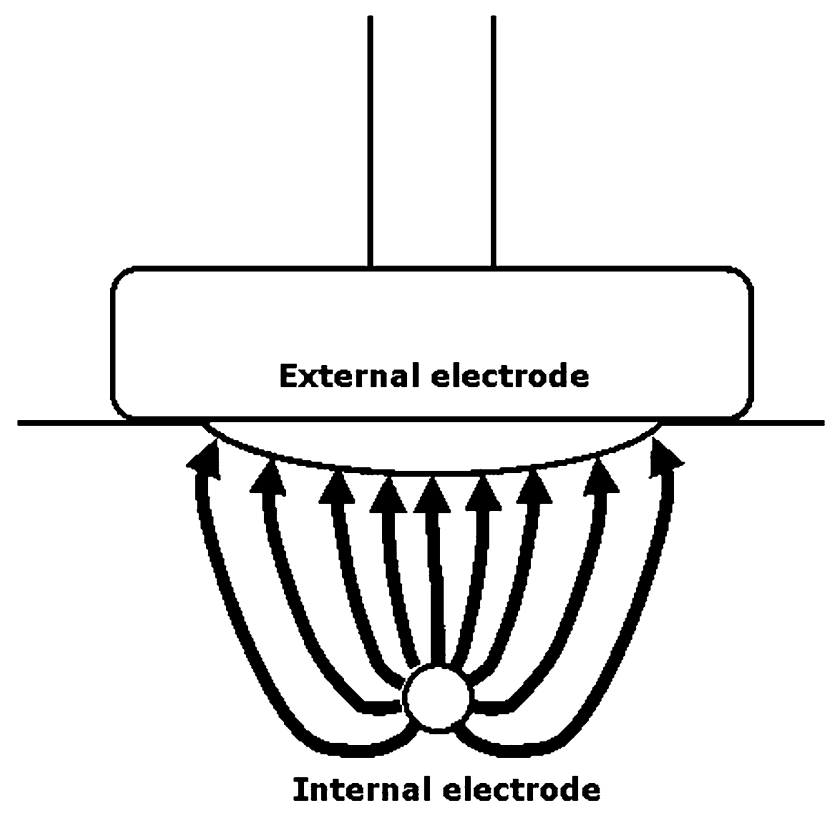

Fig. 2 Power distribution between electrodes

corresponded to the length of the internal electrode and were selected to ensure a quick uniform adipose and vascular coagulation and a rise in temperature. Zones were selected and marked on the patient's body. The cutoff temperature was set as high as $42^{\circ} \mathrm{C}$. When measured skin temperature reached this thermal target point, the device automatically cut off the power and restored power only when the temperature fell below the preset value. The power used for treatment in each zone was set initially to $20 \mathrm{~W}$ and increased gradually up to $50 \mathrm{~W}$ if no warning signs such as temperature spikes, erythema, or intradermal vesicles were observed. After determination of the maximal safety power level, the zone was treated with RFAL until the temperature-controlled power cutoff limit was reached, which then was maintained at this level for 1 to 2 min to ensure uniform heating. Typical treatment power was 40 to $45 \mathrm{~W}$.

Two depth settings were used for the treatment. The depth of 30 to $45 \mathrm{~mm}$ was used for treatment of deep fat. The end point for deep fat was reduction of mechanical tissue resistance. The superficial layer then was treated using a depth preset at 10 to $25 \mathrm{~mm}$. A uniform desired tissue temperature elevation was the indication of successful treatment.

After the RF treatment, aspiration of the coagulated adipose tissue was performed using a standard vented microcannula. Aspiration and contouring of the zone was completed when the "pinch and roll" test indicated symmetric, even, and uniform fat reduction. Fat thickness, treated area, and total applied energy were documented to determine the volumetric RF dose required to perform the treatment according to the aforementioned criteria.

\section{Results}

We compared the thermal effect created using RFAL BodyTite technology with the effect of LAL (SmartLipo MPX, Cynosure, Westford, MA) as the standards for thermal and nonthermal lipolysis and lipoplasty. For the speed of treatment, the gold standard remains PAL (Microaire Surgical Instruments, Charlottesville, VA).

\section{Treatment Speed}

The initial temperature of the treatment sites varied from 26 to $29^{\circ} \mathrm{C}$. At a power output of $45 \mathrm{~W}$, it took approximately 8 to $12 \mathrm{~min}$ to heat up a typical zone with a thermal zone of $15 \times 10 \mathrm{~cm}$ and a thickness of $25 \mathrm{~mm}$. This treatment speed of uniform heating is much faster than that of the available LAL devices. We believe that the high speed of treatment is achieved not only by the higher power of the device, but also from the more efficient use of applied power, which is not scattered from the treatment tip in all directions but concentrated in the treated zone between the two electrodes. The high speed of tissue heating facilitates the treatment of patients with large or multiple anatomic zones. In the current study, the treatment speed was comparable with that of ultrasoundassisted liposuction devices, but we believe that combination RFAL handpieces with simultaneous aspiration will make the treatment speed comparable with that of PAL.

Volumetric analysis of applied energy and treated volume showed that approximately $50 \mathrm{~J} / \mathrm{cm}^{3}$ is required to reach the needed thermal effect in a lipoplasty zone of standard size. At an RF power of 40 to $50 \mathrm{~W}$, the speed of volumetric treatment is in the range of 1 to $1.2 \mathrm{~s} / \mathrm{cm}^{3}$. 


\section{Ease of Use}

For a thermal sensor embedded in the external electrode, anticarbonization protection of the internal electrode and treatment depth control makes treatment safe, effective, and easy.

\section{Uniformity of Temperature Distribution}

Figure 3 shows the typical temperature distribution for an LAL treatment zone $(5 \times 5 \mathrm{~cm})$ when an external infrared thermometer (Raytek Corporation, Santa Cruz, CA) indicates the required target temperature of $40^{\circ} \mathrm{C}$. It can be seen that the LAL temperature distribution is not completely uniform and is concentrated in "hot spots." Although the hot spots reach temperatures of $47^{\circ} \mathrm{C}$, a significant part of the thermal zone is still cold and exhibits temperatures of below $35^{\circ} \mathrm{C}$. Application of additional LAL energy creates a high risk of a burn in the "hot spots," but ceasing treatment may lead to lack of uniform heating, poor skin contraction, and inconsistency of the results.

Using the temperature, impedance, and power control of the BodyTite device, we developed a new technique in which treatment is sustained at the target temperature for
Fig. 3 Typical thermal image of the zone treated with laserassisted lipolysis (LAL)

Fig. 4 Typical thermal image of the zone treated with radiofrequency-assisted liposuction (RFAL)
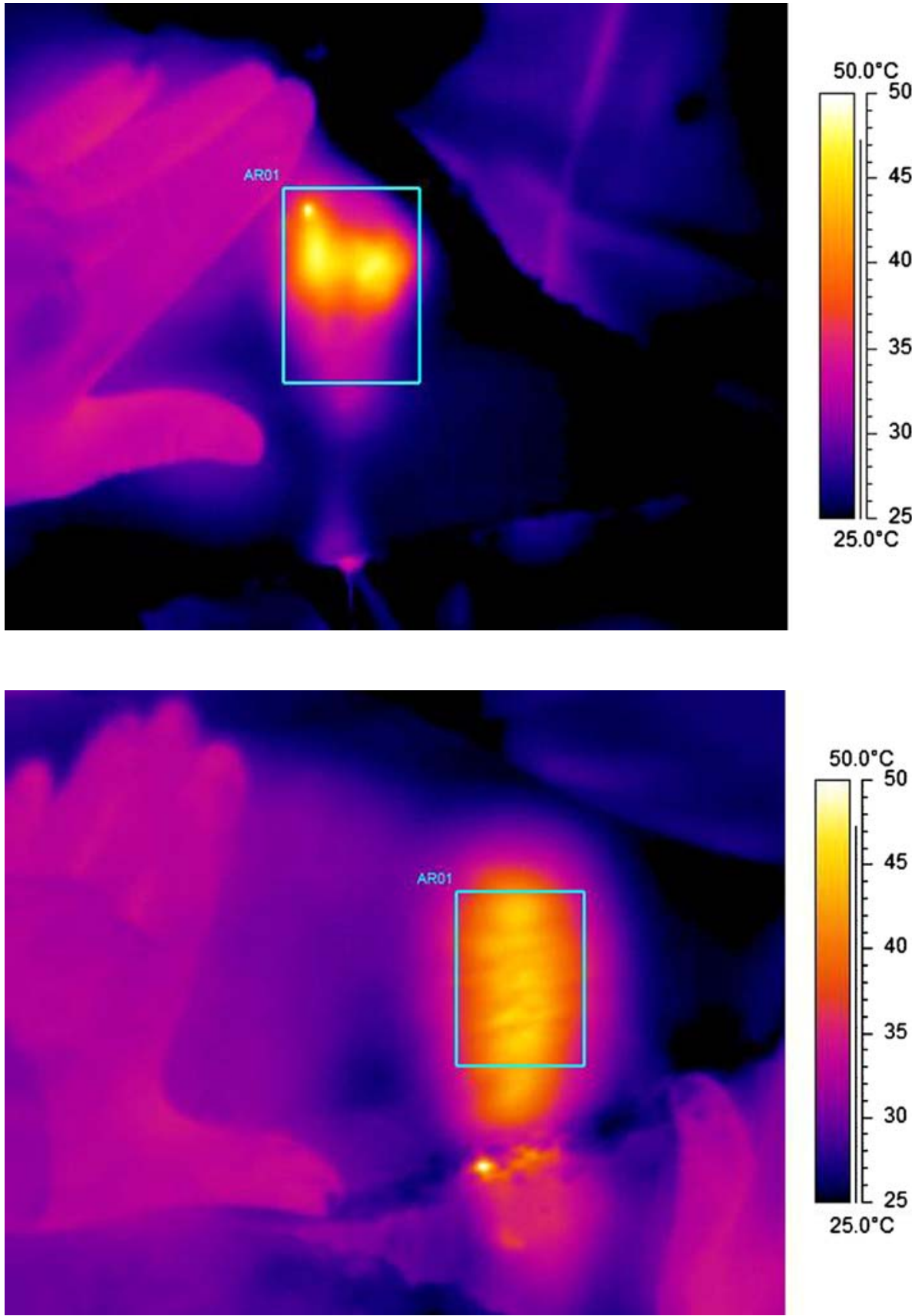
the treatment period at subnecrotic thermal levels to optimize soft tissue contraction. Closed-loop temperature and impedance control prevent thermal injury and facilitate longer treatment times at critical target temperatures, allowing all soft tissue in the treatment zone to reach a uniform temperature distribution. Figure 4 shows the uniformity of the temperature distribution after a BodyTite RFAL treatment.

The histogram in Fig. 5 obtained using Researcher 2.9 software for analysis of all thermal images shows

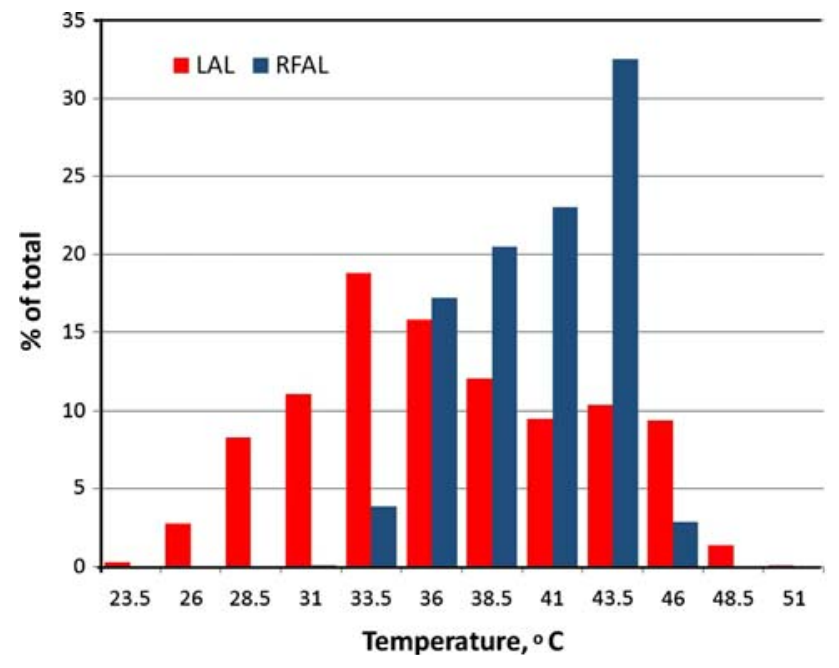

Fig. 5 Temperature distribution in the thermal zone after treatment uniformity of the treatment. It can be seen that the temperature distribution in the treatment zone after RFAL treatment exhibits twice the uniformity achieved during LAL.

\section{Fat Necrosis}

Histologic samples taken from the treated area show extensive destruction and coagulation of the adipocytes and adipose tissue. Figure 6 shows histologic images of fat from control biopsy (Fig. 6a) and posttreatment zones. Trichrome staining of the samples shows disruption and coagulation of adipocyte membranes and adipose tissue after the RFAL treatment (Fig. 6c).

It can be seen that PAL creates channels in the adipose tissue with strong bleeding (Fig. 6b). Erythrocytes fill most of the space between fat cells. After RF-assisted treatment, the channel is free of blood, and strong fat cell membrane defragmentation is observed.

\section{Blood Vessel Coagulation}

Observation of post-RFAL-treated tissue after abdominoplasty shows no bleeding in the adipose fatty tissue to a 5- to 30-mm depth, whereas bleeding is observed from blood vessels in the subdermal area, as shown in Fig. 7. Histologic analysis of blood vessels in the RFAL-treated
Fig. 6 Adipose tissue from the control biopsy (a), after PAL (b), and after radiofrequencyassisted liposuction (RFAL) (c)
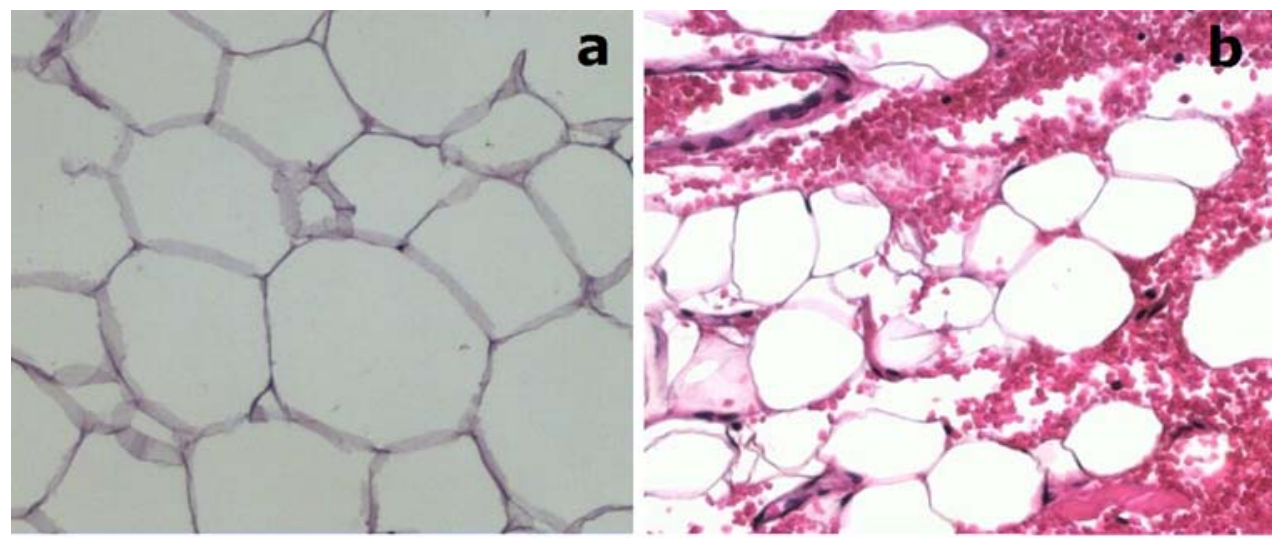

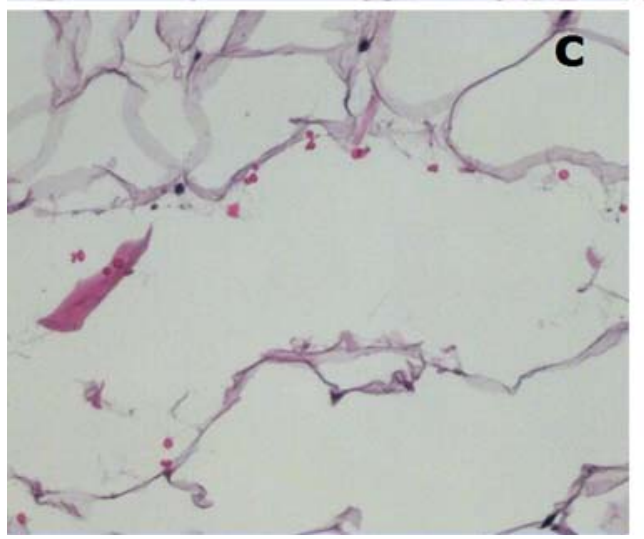




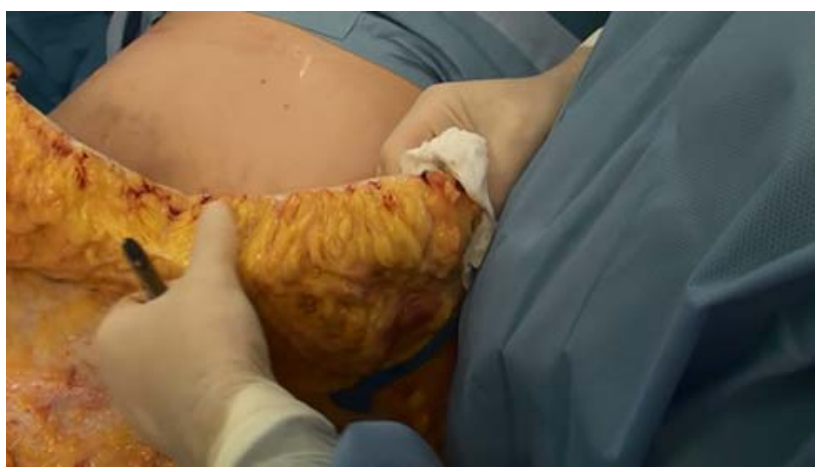

Fig. 7 Cross-section of treated adipose tissue

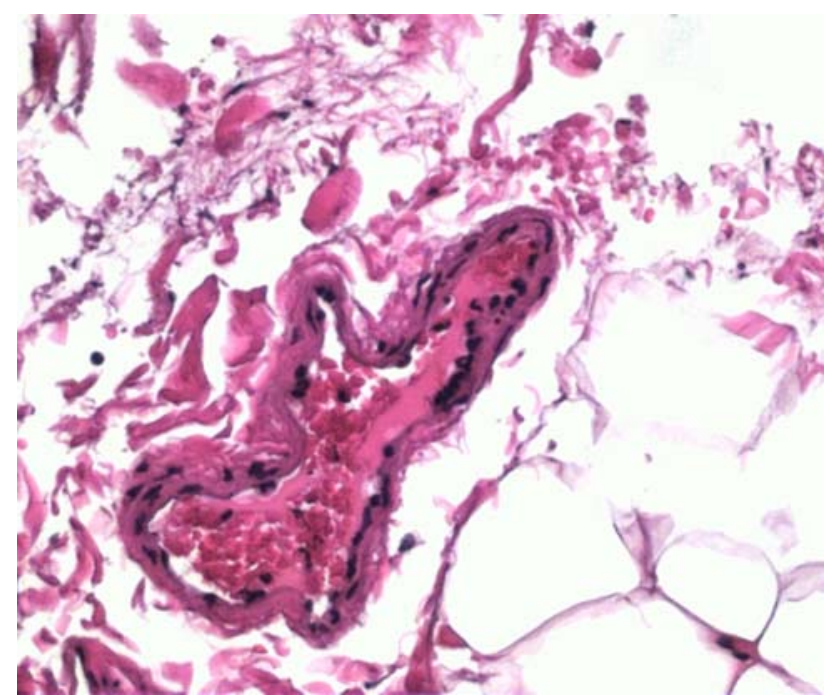

Fig. 8 Blood vessel from the radiofrequency-assisted liposuction (RFAL)-treated subcutaneous layer

zone shows coagulation of small and medium-sized blood vessels, whereas the subdermal plexus vessels are not damaged (Fig. 8).

\section{Collagen Tissue and Skin Contraction}

Histologic observation of connective tissue in the treatment area shows significant change in its structure, with coagulation of deep, reticular dermal collagen (Fig. 9). Early RFAL-induced soft tissue contraction appears very favorable and is better characterized and quantified with a longterm follow-up evaluation of 6 months. It appears that a powerful contraction and retraction of the entire subcutaneous fibrous and dermal matrix occurs after the RFAL thermal stimulation that can lead to impressive threedimensional soft tissue contraction and contours (Figs. 10, $11,12)$. We believe the necessary physiologic thresholds and criteria for soft tissue contraction, specifically maintenance of a critical temperature for a critical duration in the fibrous tissue of the adipose and subdermal regions, are optimized with the advanced BodyTite feedback controls.

\section{Treatment Safety}

No complications or any long-lasting negative side effects were observed for any patients. All the patients experienced minimal pain, swelling, and ecchymosis. It is postulated that the reduced bruising observed was due to blood vessel coagulation in the treated zone before aspiration. The feedback control in the BodyTite handpiece allowed for the necessary sustained tissue heating to 40 to $42^{\circ} \mathrm{C}$ without thermal injury.

\section{Discussion}

Radiofrequency-assisted liposuction is a promising technology for body contouring with the following apparent advantages:

- Ability to heat a significant volume of tissue quickly and uniformly
Fig. 9 Collagen appearance. Control condition (a) and immediately after the treatment (b)
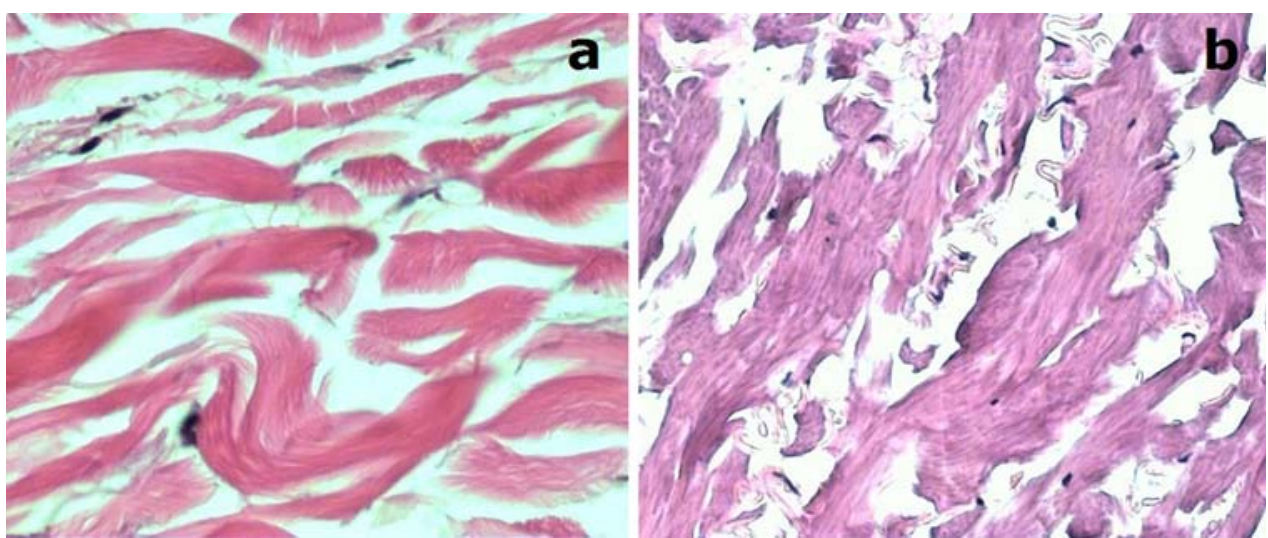
Fig. 10 Body shape appearance of a female patient before (left) and 6 months after treatment (right)

Fig. 11 Body shape appearance of a female patient before (left) and 6 months after treatment (right)

Fig. 12 Body shape appearance of a female patient before (left) and 6 months after treatment (right)
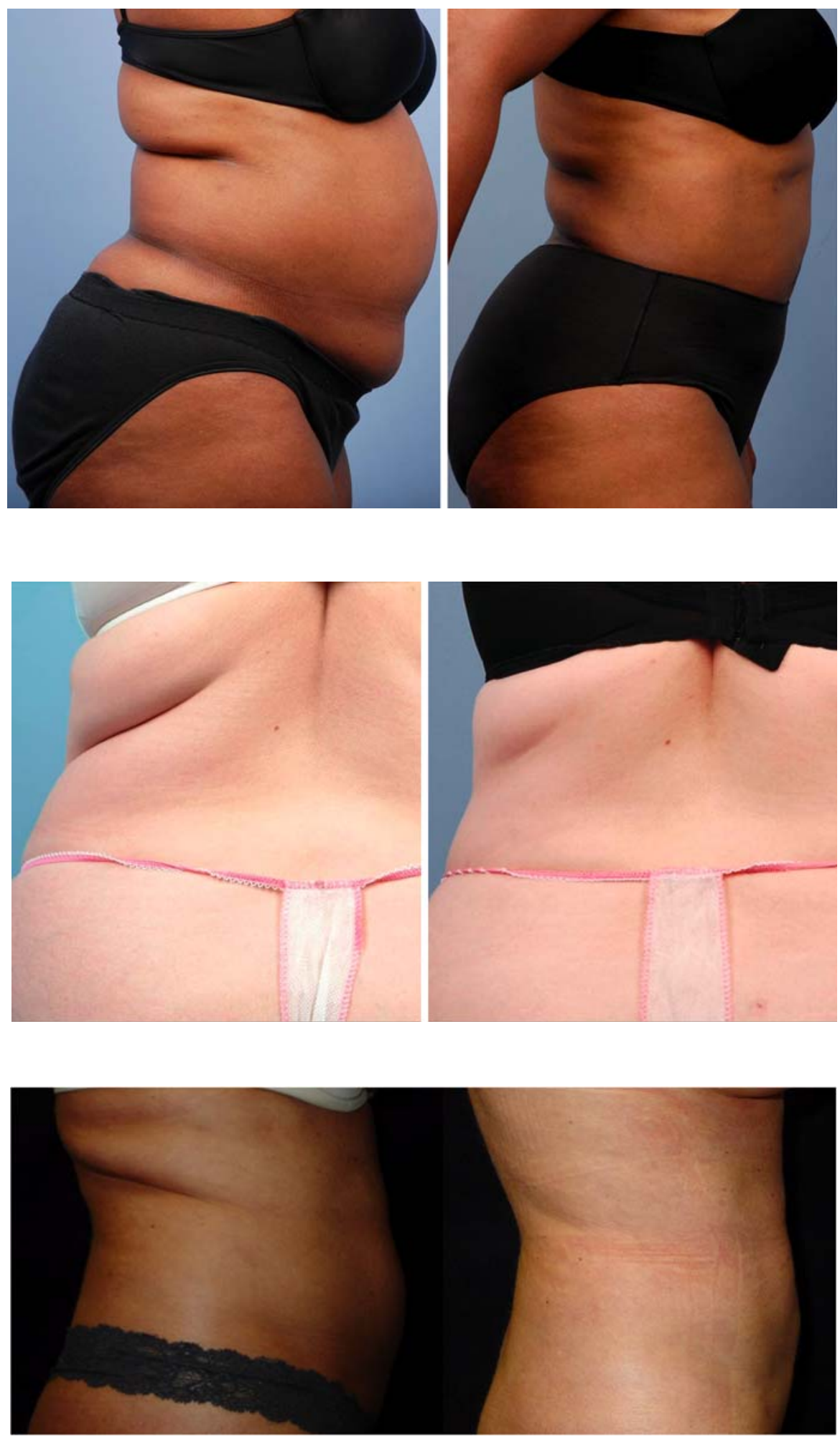

- Ability to control tissue heating through direct monitoring of temperature and tissue impedance.

- Defragmentation of fat cells and coagulation of blood vessels in the treated zone, reducing bleeding and bruising

- Obvious collagen denaturation after RFAL treatment
- Significant contraction and retraction of adipose and dermal tissue after treatment.

The correlation between tissue-heating temperature, time, and body tightening requires further investigation but 
appears to offer an exciting new vista in nonexcisional body contouring.

Acknowledgment We thank Invasix Ltd for assistance in thermal measurements, and we appreciate Patricia Ganas for her assistance with preparing this report for publication. The chief of medical advisory board was compensated for fees and options by Invasix Ltd.

Open Access This article is distributed under the terms of the Creative Commons Attribution Noncommercial License which permits any noncommercial use, distribution, and reproduction in any medium, provided the original author(s) and source are credited.

\section{References}

1. Badin AZ, Moraes LM, Gondek L, Chiaratti MG, Canta L (2002) Laser lipolysis: flaccidity under control. Aesth Plast Surg 26:335339

2. Beckenstein MS, Grotting JC (2000) Ultrasound-assisted liposuction using the solid probe: a retrospective review of 100 consecutive cases. Plast Reconstr Surg 105:2161-2174

3. Fodor PB, Vogt PA (1999) Power-assisted lipoplasty (PAL): a clinical pilot study comparing PAL to traditional lipoplasty (TL). Aesth Plast Surg 23:379-385

4. Fournier PF, Otteni FM (1983) Lipodissection in body sculpturing: the dry procedure. Plast Reconstr Surg 72:598-609

5. Gasparotti M (1992) Superficial liposuction: a new application of the technique for aged and flaccid skin. Aesth Plast Surg 16:141153

6. Gasperoni C, Salgarello M, Emiliozzi P, Gargani G (1990) Subdermal liposuction (related articles, links). Aesth Plast Surg 14:137-142

7. Goddio AS (1991) Skin retraction following suction lipectomy by treatment site: a study of 500 procedures in 458 selected subjects. Plast Reconstr Surg 87:66-75

8. Goldman A (2006) Submental Nd:YAG laser-assisted liposuction. Lasers Surg Med 38:181-184
9. Hetter GP (1984) Optimum vacuum pressures for lipolysis. Aesth Plast Surg 8:23-26

10. Ichikawa K, Miyasaka M, Tanaka R, Tanino R, Mizukami K, Wakaki M (2005) Histological evaluation of pulsed Nd:YAG laser for lipolysis. Lasers Surg Med 36:43-46

11. Illouz YG (1983) Body contouring by lipolysis: a 5-year experience with over 3,000 cases. Plast Reconstr Surg 72:591-597

12. Kesserlring UK (1983) Regional fat aspiration for body contouring. Plast Reconstr Surg 72:610-619

13. Klein JA (1990) The tumescent technique: anaesthesia and modified liposuction technique. Deramatol Clin 8:425-437

14. Klein JA (1993) Tumescent technique for local anaesthesia improves safety in large-volume liposuction. Plast Reconstr Surg 92:1085-1098

15. Kloehn RA (1996) Liposuction with "sonic sculpture": six years experience with more than 600 patients. Aesth Surg Q 16:123-128

16. Matarrasso A (1995) Superficial suction lipectomy: something old, something new, something borrowed. Ann Plast Surg 24:268-272

17. Pitman GH (1993) Tumescent technique for local anaesthesia improves safety in large-volume liposuction, by J. A. Klein (discussion). Plast Reconstr Surg 92:1099-1100

18. Pitman GH (1995) Tumescent technique in liposuction. Plast Reconstr Surg 95:612-613

19. Prado A, Andrades P, Danilla S, Leniz P, Castillo P, Gaete F (2006) A prospective, randomized, double-blind, controlled clinical trial comparing laser-assisted lipoplasty with suctionassisted lipoplasty. Plast Reconstr Surg 118:1032-1045

20. Rohrich RJ, Beran SJ, Kenkel JM, Adams WP Jr, DiSpaltro F (1998) Extending the role of liposuction in body contouring with ultrasound-assisted liposuction. Plast Reconstr Surg 101:1090 1102

21. Teimourian B (1982) Suction curettage to remove excess fat for body contouring. Plast Recent Surg 68:50-58

22. Toledo LS (1991) Syringe liposculpture: a two-year experience. Aesth Plast Surg 15:321-326

23. Zocchi ML (1992) Ultrasonic liposculpturing. Aesth Plast Surg $16: 287-298$

24. Zocchi ML (1996) Ultrasonic assisted lipoplasty: technical refinements and clinical evaluations. Clin Plast Surg 23:575-598 